\title{
O PROCESSO DE COMPRAS: UM ESTUDO TEÓRICO DE SUA RELAÇÃO COM O CICLO PRODUTIVO DA INDÚSTRIA DO VESTUÁRIO
}

\section{THE PURCHASE PROCESS: A THEORETICAL STUDY OF ITS RELATIONSHIP WITH THE PRODUCTION CYCLE OF THE CLOTHING INDUSTRY}

\author{
Marcio José Silva*E-mail: mjsilva2@uem.br \\ Eliane Pinheiro*E-mail: epinheiro@uem.br \\ Cláudia Herrero Martins Menegassi** E-mail: claudiaherrero@gmail.com \\ *Universidade Estadual de Maringá (UEM), Maringá, PR \\ ${ }^{* *}$ Centro de Ensino Superior de Maringá (Unicesumar), Maringá, PR
}

\begin{abstract}
Resumo: A área de compras tem importância estratégica para os negócios dos diversos setores, inclusive para as indústrias de vestuário, que exige um olhar sob suas especificidades. Este trabalho tem como objetivo analisar como o processo de compras está inserido no ciclo produtivo da indústria do vestuário identificando as relações existentes com outros processos. O delineamento utilizado foi uma pesquisa exploratória de caráter qualitativo, a partir da busca em publicações existentes sobre o tema. Descobriu-se que há lacunas sobre o processo de compras em publicações da área de moda, que o setor de compras atua juntamente com outros setores com a finalidade de suprir o curto ciclo produtivo, que esse setor é responsável por criar informações importantes para o processo produtivo. A partir disso o estudo apresenta um esquema que contempla a inserção do processo de compras no ciclo produtivo da indústria do vestuário. Esse resultado é importante por destacar a importância da área de compras para o setor de vestuário e consequentemente beneficia as discussões em torno da cadeia de suprimentos.
\end{abstract}

Palavras-chave: Processo de Compras. Indústria do Vestuário. Ciclo Produtivo.

Abstract: The purchase area has strategic importance for the business of the various sectors, including for the clothing industries, which requires a look under its specificities. This article aims to analyze how the purchasing process is inserted in the productive cycle of the clothing industry, identifying the existing relationships with other processes. The design used was an exploratory research of qualitative character, from the search in existing publications on the subject. It was found that there are gaps in the purchasing process in fashion publications, that the purchasing sector works together with other sectors with the purpose of supplying the short production cycle, that this sector is responsible for creating important information for the process productive. From this the study presents a scheme that contemplates the insertion of the purchasing process in the productive cycle of the clothing industry. This result is important because it emphasizes the importance of the shopping area for the apparel sector and consequently benefits the discussions around the supply chain.

Keywords: Purchase Process. Clothing Industry. Productive Cycle.

\section{INTRODUÇÃO}

setor têxtil e vestuário é de grande importância tanto para os países

industrializados quanto para as economias menos desenvolvidas como, por 
exemplo, Vietnã, Bangladesh, Turquia, Paquistão, Indonésia e Brasil e, contribui para a geração de riqueza e emprego (BRUCE et al., 2004). Na economia brasileira o setor é reconhecido pela representatividade na criação de empregos e renda, movimentando algo em torno de US\$ 40 bilhões ao ano. O país conta com um parque produtivo que abarca cerca de 30 mil empresas, tornando o país o quarto maior produtor de vestuário do mundo, com uma produção que ultrapassa os 5 bilhões de peças ao ano (ABIT, 2017).

Neste estudo a ênfase é sobre a indústria do vestuário - que beneficia os artigos têxteis em produtos de diferentes segmentos de uso. Essas indústrias estão inseridas em um mercado altamente competitivo e isso exige dessas indústrias, caracterizadas geralmente por pequenas e médias empresas, a necessidade de adequar suas estratégias a fatores específicos como as interferências criadas pelas tendências de moda, o curto ciclo produtivo, alta volatilidade do mercado, baixa previsibilidade de demanda e um alto nível de compra por impulso (BRUCE et al., 2004; MACCHION et al., 2014; CHAN et al., 2017).

Nesse sentido a gestão da cadeia de fornecimento é vital para alinhar os processos produtivos, criar possibilidades de negócios e lidar com os desafios ocasionados pelo aumento da concorrência (SCHOENHERR, 2012). Contudo é imprescindível ao falar em cadeia de fornecimento não mencionar o processo de aquisição de materiais, que é realizado por meio da área de compras.

O processo de compras compreende várias etapas (pesquisa, negociação, análise de estoques, emissão de pedidos, conferência das chegadas) e além disso são executadas com diferentes fornecedores, já que na maioria dos casos é necessário a seleção de uma fonte diferente e específica, de fornecimento (SILVA et al., 2018). As atividades principais atribuídas à área de compras de materiais são: seleção de fornecedores confiáveis e que forneçam produtos com boa qualidade a preço justo, análise de ordens de pedidos, controle de itens já adquiridos e redução de custos de aquisição (POZO, 2007; TACCONI et al., 2014). Essas atividades não são, propriamente, regras ou diretrizes para essa área, mas sim ações básicas que de acordo com o tipo de negócio irão se desenvolvendo e seguindo seus próprios critérios.

A gestão da cadeia de suprimentos, por meio da área de compras, se mostra como essencial para atender ao modelo de negócios contemporâneo, onde as 
empresas precisam se manter competitivas mesmo com o curto ciclo de vida dos produtos, gerir os negócios a fim de satisfazer as expectativas dos clientes, lidar com a concorrência e estabelecer parcerias de fornecimento (SCHOENHERR, 2012; TACCONI et al., 2014). No contexto do vestuário, de acordo com Thomassey (2010), fatores como sazonalidade das vendas, poder de compras dos consumidores, criação de produtos de estilo - que tem ciclo de vida extremamente curto -, dificuldade no levantamento de históricos de venda e extensão do mix de produtos, são fatores relevantes a serem considerados diante a outros tipos de negócio. Esses fatores certamente criam desafios para a aquisição dos materiais, o que torna o setor de compras fundamental para alinhar isso a uma aquisição de materiais segura (SILVA et al., 2018).

Apesar de se apresentar como um setor estratégico, há pouca discussão na literatura sobre o processo de compras inserido ao contexto do vestuário. Em análise a literatura básica da área de moda - como Jones (2005) e Treptow (2013) -, observa-se que o processo de compras é tratado de maneira superficial, o que não condiz com o tipo de indústria ao qual está inserido.

Diante do contexto apresentado, o objetivo deste trabalho é analisar como o processo de compras está inserido no ciclo produtivo da indústria do vestuário analisando as relações existentes com outros processos. Para tanto, será discutido os processos produtivos da indústria do vestuário e o processo de compras, de modo geral e sobre a perspectiva do vestuário.

A análise da inserção do processo de compras no setor do vestuário é demonstrada a partir da proposição de um esquema que apresenta a incidência de atividades desse setor no ciclo produtivo da indústria do vestuário. O trabalho se desenvolve em discussão teórica, procedimentos metodológicos, discussão e apresentação dos resultados e considerações finais.

\section{OS PROCESSOS PRODUTIVOS DA INDÚSTRIA DO VESTUÁRIO}

Para Rech (2008) a indústria de vestuário é composta por uma sequência de atividades, que se iniciam ainda na indústria têxtil, passando pela confecção dos produtos que abrange a criação, a modelagem, o enfesto, o corte, a costura e 0 beneficiamento do produto e pôr fim a entrega ao consumidor final. Andrade, 
Bezerra e Ladim (2015) indicam que na indústria do vestuário há pelo menos sete etapas produtivas sendo: criação, modelagem, prototipagem, corte, costura, acabamento e expedição. Em complemento a isso Silva (2017) identifica treze atividades que fazem parte do processo de desenvolvimento de produto, ou do a ciclo produtivo da indústria do vestuário. Nesse mesmo sentido Silva et al., (2018) afirmam que o setor de compras necessita estabelecer relações com diferentes setores, que vão desde a área de criação até a distribuição.

Em ambas as abordagens se percebe que as atividades descritas, são comuns ao tipo de negócio, ou seja, independente do porte da empresa ou do tipo de comercialização há atividades que necessitam ser executadas. Podendo ser mencionado a criação, modelagem, aquisição de materiais, risco, corte, enfesto, costura e distribuição. Isso significa que em muitos casos é difícil identificar qual a quantidade exata de processos ou setores existentes ou se há uma ordem de execução, já que isso depende do porte, do tipo de organização e até mesmo dos recursos financeiros para desmembrar os processos em mais ou menos setores.

De acordo com Silva (2017), as atividades podem ser divididas em dois grupos o de desenvolvimento e o de produção, sendo que a criação, modelagem, prototipagem e engenharia de produto - ou análise de qualidade - estão ligadas ao desenvolvimento do projeto e as atividades de compras, planejamento e controle de produção (PCP), almoxarifado, encaixe, corte, costura, acabamento e expedição, estão ligados a produção, ou seja a execução do projeto. Silva et al., (2018) corroboram com essa afirmação, o que leva ao entendimento do que é tratado por Thomassey (2010), Kachba e Hatakeyama (2015), Yang, Qi e Lin (2015), Kachba e Hatakeyama (2015), Andrade, Bezerra e Ladim (2015) e Silva (2017) de que esse tipo de indústria possui processos fragmentados.

Em análise a literatura específica da área de moda, observa-se algumas lacunas na abordagem sobre o ciclo produtivo da indústria do vestuário, ao se falar na aquisição dos materiais. Jones (2005) indica a compra dos materiais, no entanto não apresenta claramente qual é a origem dessa compra, ou seja, qual o setor responsável por gerar a demanda. Já Treptow (2013) menciona sobre o armazenamento dos materiais, no entanto, fica a dúvida sobre qual a origem do material a ser armazenado, qual processo ou setor é o responsável pela aquisição desse material. Em suma, o que se observa é que os estudos sobre o processo 
produtivo da indústria do vestuário enfatizam o processo de criação do produto, fato que se entende como relacionado a essa área ser a primeira que compõe o processo produtivo.

Desse modo é possível apresentar que em relação às demandas iniciais de compras - quais produtos serão utilizados - isso parte do setor de criação ou dos estilistas, após isso em relação aos quantitativos reais de aquisição isso pode ser feito por meio de ações conjuntas entre os setores que controlam a produção, o setor de vendas e até mesmo o de compras (TYLER; HEELEY; BHAMRA, 2006; SILVA et al., 2018).

Os processos que compõem a estrutura produtiva da indústria do vestuário e que são sequentes ao setor de criação, poderão conter atividades relacionadas ao controle de qualidade e serviço de terceiros, por exemplo. Nesse contexto se deve avaliar que o tempo é um dos principais fatores que desfavorecem o setor do vestuário, já que os produtos são criados a partir de tendências de moda, e essas tendências são cíclicas e passageiras (JONES, 2005; SILVA, et al., 2018). Portanto o ciclo de vida tanto produtivo quanto dos produtos é extremamente curto, tornando complexa a tomada de decisões e criando a necessidade de antecipação de processos produtivos, aquisição de materiais, planejamento do período de produção, de vendas e assim por diante (TURKER; ALTUNTAS, 2014; ČIARNIENÉ; VIENAŽINDIENÉ, 2014; TYLER; HEELEY; BHAMRA, 2006; THOMASSEY, 2010).

Devido a fragmentação dos processos e o grande número de envolvidos, obter respostas de modo ágil se torna um dos pontos mais relevantes e de vantagem competitiva para essas empresas. Para isso podem ser aplicadas estratégias como a capacitação de pessoas, implantação de sistemas de informação e atividades ligadas à melhoria de produtividade (YANG; QI; LI, 2015). Nesse sentido a disponibilidade de matérias-primas em tempo hábil contribui não só para a abastecer a produção e evitar gargalos produtivos, mas também para que as demais etapas produtivas sejam capazes de dar continuidade a seu trabalho (SILVA, 2017; SILVA et al., 2018). Assim o setor de compras vem a ser o responsável não só pela aquisição dos materiais, mas também por realizar negociações, evitar a aquisição de materiais desnecessários e alinhar a cadeia de fornecimento à produtiva. 


\subsection{O processo de compras no contexto do vestuário}

As empresas de modo geral, não são autossuficientes na geração de todos os recursos que necessitam para administrar seus negócios. Para que isso ocorra é necessário a criação de parcerias para a aquisição de bens ou serviços que irão suprir as demandas produtivas. Essas parcerias são criadas por meio do setor de compras, que é o responsável pela negociação e aquisição de todos os itens que serão utilizados na produção (TACCONI et al., 2014).

Em abordagem sobre o papel do comprador, em redes de varejo de moda, Shaw e Koumbis (2014) mencionam sobre a relação que o comprador necessita ter com diferentes envolvidos. De acordo com os autores as parcerias devem prever relações internas e externas - fornecedores em potencial, equipe de vendas, representantes de tecidos, designers - de modo a abranger qualquer elemento que possa, de alguma forma, exercer influência sobre o processo de compras. Desse modo o comprador assume um papel verdadeiramente estratégico nos negócios e cada vez mais central na gestão dos recursos da empresa, incorporando-se à rede de suprimentos e a tecnologia da informação (CIPRIANI JR et al., 2015; DELALIBERA; LIMA; TURRIONI, 2015).

O processo de compras é composto de atividades que têm a finalidade de adquirir matérias-primas de maneira ágil, reduzir os custos de aquisição, manter a continuidade do abastecimento, realizar o controle dos itens já adquiridos e os que devem ser adquiridos, manter contato constante com fornecedores, realizar pesquisas de novas fontes de fornecimento, reduzir os índices de inventário, manter estoques de segurança - quando isso não gerar ociosidade de materiais -, e analisar o mercado (POZO, 2007; CIPRIANI JR et al., 2015).

Determinadas atividades são básicas e independente do tipo de negócio serão praticadas durante o processo de aquisição. As atividades consideradas básicas são: seleção de fornecedores confiáveis, análise de oferta de produtos com boa qualidade a preço justo, análise de ordens de pedidos, controle de itens adquiridos, redução dos custos de aquisição (POZO, 2007; TACCONI et al., 2014). O critério para estabelecer essas atividades é criado internamente e isso pode variar de empresa para empresa, por exemplo, a partir da criação de manuais contendo regras de seleção de fornecedores ou qualidade dos materiais. No entanto neste 
trabalho não se prioriza determinar ou apresentar um modelo de regras de fornecimento.

No contexto do vestuário, um dos critérios que deve ser avaliado, no processo de compras, é o prazo de entrega dos produtos, já que os prazos de permanência dos produtos no mercado é bastante reduzido, uma coleção de vestuário pode ser desenvolvida entre quatro e dez meses, isso já considerando todos os processos ou atividades já descritos neste trabalho (SEN, 2008; KACHBA; HATAKEYAMA, 2015). Isso significa que dentro do prazo de uma coleção a não disponibilidade dos materiais pode acarretar na não entrega dos produtos dentro do cronograma de produção, o que pode gerar sobra de produtos acabados ou não, no caso dos materiais não beneficiados esses dificilmente serão utilizados caso sejam característicos de uma determinada tendência de moda ou estação do ano (ČIARNIENE்; VIENAŽINDIENĖB, 2014; CIPRIANI JR et al., 2015).

Para lidar com o curto ciclo produtivo uma das possibilidades, descritas pela literatura, é a escolha de fornecedores confiáveis e competitivos no mercado. Para avaliar um fornecedor, Jones (2005) indica a necessidade de verificar se os preços e prazos de entrega serão respeitados, se o fornecedor mantém bom relacionamento comercial e de qualidade. Neste mesmo sentido Hallikas e Lintukangas (2016), indicam que a seleção dos fornecedores deve prever uma relação de parceria com objetivos de longo prazo, como o estabelecimento de normas de fornecimento, isso tende a promover o desenvolvimento da cadeia de fornecimento.

A criação de normas ou critérios de fornecimento, de acordo com Turker e Altuntas (2014), devem objetivar a criação de uma cadeia de suprimentos enxuta e flexível, deste modo necessita priorizar os fornecedores que estejam dispostos a tomada de decisões em conjunto, sendo esse um dos critérios a ser avaliados para a seleção de um fornecedor. Outro fator a ser verificado em relação ao fornecimento é o de diminuir fatores ligados a ótica negativa da produção em massa, como os ambientais, sociais e o aumento dos custos de produção.

A relação principal do critério de seleção de um fornecedor, segundo Yang, Qi e Li (2015) é a verificação do tempo de resposta desses fornecedores, já que em determinados tipos de produção - no caso as indústrias de vestuário - faz-se necessário obter rapidamente informações, para que o processo transcorra sem interrupções. Nesse sentido explorar as capacidades e limitações do fornecedor 
torna o processo de aquisição mais ágil contribuindo para que a empresa responda prontamente às potenciais mudanças no mercado (MOON; YI; NGAI, 2012). Nesse sentido destaca-se que os critérios a serem definidos para a seleção de fornecedores confiáveis, deve ser estabelecido de acordo com os objetivos e necessidades das empresas. Contudo alguns desses se mostram como fundamentais: custo total de aquisição; qualidade dos produtos; qualidade da informação prestada; capacidade de solucionar problemas e disponibilidade para trabalho em conjunto (MOON; YI; NGAI, 2012; HALLIKAS; LINTUKANGAS, 2016; TURKER; ALTUNTAS, 2014)

Em análise ao sistema de compras, Pozo (2007, p.159) discorre que esse "baseia-se em uma ação que envolve atividades de pesquisas para a melhor adequação dos objetivos organizacionais". Essas pesquisas devem contemplar fatores associados à inovação tecnológica, oscilação da economia e novas fontes de fornecimento, englobando um processo de mudanças planejadas que irão se adequar e auxiliar em ganhos tangíveis ou não para a própria empresa (LIMA et al., 2012). Entre esses ganhos pode-se mencionar além dos lucros, a manutenção das vendas, a qualificação profissional e a melhoria dos métodos ou processos de trabalho.

Em relação a habilidade necessária para o profissional de compras, Tacconi et al., (2014) indica a necessidade de que esse profissional tenha visão geral ou holística dos negócios, não se limitando apenas a uma atividade, que geralmente é associada a redução dos custos de aquisição. A visão holística proporciona melhores ganhos para a empresa já que esse profissional não se limita ao seu setor e ao analisar diferentes perspectivas de negociação, como o custo total de aquisição, que envolve desde o preço até a qualidade do produto, proporciona resultados concisos contribuindo para a organização da cadeia de suprimentos.

No setor do vestuário essa percepção abrangente da cadeia de suprimentos e do tipo de negócio é fundamental principalmente no sentido de que o comprador deve considerar o lead-time, que é o tempo total de produção. Os itens de vestuário são apresentados em estações do ano e a duração desses produtos é medida em meses ou até mesmo semanas; raramente haverá uma venda estável por longos períodos ou produtos considerados básicos, que utilizem materiais que se repitam em mais que uma coleção (ČIARNIENÉ; VIENAžINDIENÉB, 2014; MONDINI et al., 
2015). Compreender toda a sistematização do processo produtivo da indústria do vestuário irá auxiliar o comprador a organizar a compra e a chegada dos produtos, contribuindo para que possa gerir os estoques, evitando a compra em excesso, que gera estoques ociosos, ou a falta de compra de materiais, que cria as paradas de produção.

A fabricação de uma roupa é composta por um sistema de previsões, logística complexa e particularidades do próprio produto, segundo Thomassey (2010), uma das características nesse processo e que irá determinar demais ações a serem tomadas no processo de compras é em relação ao mix de produtos que é extenso e variado a fim de atender características estéticas e dos diferentes tipos morfológicos dos consumidores, tornando a aquisição de materiais e previsão de demanda produtiva incerta e instável.

Para Pickles et al., (2015), a localização geográfica é uma realidade a ser tratada no dia a dia de trabalho dos compradores, já que os mercados localizados em regiões distantes implicam no tempo de transporte, o que apresenta consequências diretas ao custo do produto. Silva (2017) e Macchion et al., (2014). indicam que para o setor do vestuário a cadeia de fornecimento tende a ser dispersa, já que determinadas matérias-primas são encontradas somente em determinadas regiões.

A própria dinâmica da indústria do vestuário contribui para algumas ações como a antecipação de processos e a compra de materiais por meio de previsões de demanda produtiva e venda (SILVA et al., 2018). Deste modo para atender aos prazos referentes a produção e entrega dos produtos a compra por previsão é um fato comum - independente do porte ou tipo de comercialização - existente nas empresas de vestuário (POZO, 2007; TOSETTI et al., 2008; SILVA, 2017). Talvez essa seja uma das maiores atribuições do setor de compras, no contexto do vestuário, adequar índices de materiais por meio de previsões.

Uma das estratégias então de aquisição volta-se a temática das relações a serem estabelecidas entre diferentes fontes de fornecimento - internas e externas abordadas por Shaw e Koumbis (2014) e Tacconi et al., (2014). Isso se relaciona diretamente ao objetivo deste trabalho - analisar como o processo de compras está inserido no ciclo produtivo da indústria do vestuário identificando as relações existentes com outros processos - a partir do delineamento dos setores afetos ao 
processo de compras isso pode contribuir para elaborar métodos que visem a unificação de informações.

Após a contextualização sobre o processo de compras seguem-se os procedimentos metodológicos e então os resultados que mostram a relação desse processo no ciclo produtivo da indústria do vestuário.

\section{MATERIAIS E MÉTODOS}

Este estudo concentra-se na perspectiva das indústrias de vestuário e em seus processos produtivos e organizacionais, com ênfase no setor de compras e na interação com demais setores e processos. Trata-se de uma pesquisa exploratória de caráter qualitativo, a partir da busca em publicações existentes sobre o tema.

Para a pesquisa foram usadas as bases de dados Periódicos Capes; Scielo e Elsevier por conterem publicações abrangentes sobre o tema aqui pesquisado. As palavras-chave utilizadas foram associadas entre si: "cadeia de suprimentos" AND "indústria do vestuário" AND "setor de compras". Foram identificados um número restrito de materiais com a combinação destes termos.

Foi analisado o processo de compras e sua interação com os demais processos produtivos, a fim de obter percepções que favoreçam a compreensão sobre as atividades desse setor e sua relação com o ciclo produtivo da indústria do vestuário. A análise das publicações considerou os seguintes aspectos: descrição do processo de compras; autores específicos para a área de moda e vestuário; possibilidades de associação do setor de compras à indústria de vestuário e direcionamento do estudo sobre a cadeia produtiva e de abastecimento em relação ao curto ciclo de vida de produtos.

Deste modo os resultados são analisados em duas etapas: i) elaboração de um quadro com a abordagem utilizada pelos autores em suas publicações e o entendimento de lacunas teóricas sobre o processo de compras direcionado a indústria de vestuário e; ii) elaboração de um esquema a partir do referencial teórico e do Quadro 1. Esse esquema mostra como a atividade de compras está relacionada ao ciclo produtivo da indústria do vestuário. 


\section{ANÁLISE E DISCUSSÃO DOS RESULTADOS}

O primeiro fator a ser analisado é que a maioria das publicações que apresentam alguma relação com compras vão ao encontro de comportamento de compra, que é uma outra relação muito próxima ao setor do vestuário, mas não atende ao objetivo desta pesquisa. Desse modo foi estabelecido um critério de avaliação das publicações encontradas da seguinte forma: i) publicações específicas da área de vestuário; ii) publicações referentes ao processo de compras e cadeia de suprimentos (de modo geral); iii) publicações que tratem sobre o processo de compras ou cadeia de suprimentos no setor do vestuário. Foram utilizados artigos científicos, livros e dissertação.

O Quadro 1 apresenta os trabalhos que contribuem para este estudo, apresentando a abordagem principal dos mesmos e o tipo de publicação.

Quadro 1 - Análise geral da inserção do processo de compras no setor do Vestuário (continua)

\begin{tabular}{|c|l|l|}
\hline Autor & \multicolumn{1}{|c|}{ Abordagem } & Publicação \\
\hline Jones (2005) & $\begin{array}{l}\text { É uma das referências utilizadas na área de moda, apresenta } \\
\text { um panorama geral sobre o negócio de moda e alguns } \\
\text { processos, inclusive sobre as compras, trata sobre a aquisição } \\
\text { dos materiais e que as compras de matérias-primas devem } \\
\text { atender a calendários específicos e levar em consideração o } \\
\text { curto ciclo de vida dos produtos. }\end{array}$ & Livro \\
\hline Tyler, Heeley e \\
$\begin{array}{c}\text { Bhamra (2006) } \\
\text { Piscutem como determinados fatores existentes na cadeia de } \\
\text { suprimentos interferem na competitividade do setor de } \\
\text { vestuário. Demonstrando a necessidade da criação de } \\
\text { parcerias para lidar com os fatores existentes no contexto do }\end{array}$ & Artigo \\
\hline vestuário. & $\begin{array}{l}\text { Trata sobre o processo de compras, de modo geral, } \\
\text { apresentando quais as atividades/funções atribuídas a este } \\
\text { setor, sua importância na integração gerencial da cadeia de } \\
\text { suprimentos. }\end{array}$ & Livro \\
\hline Tosetti et al., & $\begin{array}{l}\text { lrazem uma abordagem sobre a aquisição de materiais frente a } \\
\text { um ambiente de negócios com mudanças de demanda e de } \\
\text { mercado. Não sendo uma abordagem específica para indústrias } \\
\text { de vestuário. }\end{array}$ & Artigo \\
\hline Thomassey & $\begin{array}{l}\text { Investiga as práticas existentes na indústria do vestuário e } \\
\text { como se dão as análises de previsão de compras de matérias- } \\
\text { primas. Analisa em seu estudo a volatilidade dos itens de } \\
\text { vestuário e as especificidades do setor. }\end{array}$ & \\
\hline $\begin{array}{l}\text { Schoenherr } \\
\text { (2012) }\end{array}$ & $\begin{array}{l}\text { Apresenta a importância do setor de compras para a gestão da } \\
\text { cadeia de fornecimento e mostra possibilidades de pesquisas } \\
\text { para práticas que atendam aos desafios existentes nessa } \\
\text { cadeia. Não apresenta abordagem específica para indústrias de } \\
\text { vestuário. }\end{array}$ & Artigo \\
\hline
\end{tabular}


Quadro 1 - Análise geral da inserção do processo de compras no setor do Vestuário (conclusão)

\begin{tabular}{|c|c|c|}
\hline Autor & Abordagem & Publicação \\
\hline Treptow (2013) & $\begin{array}{l}\text { Referência na área de moda, apresenta um panorama geral } \\
\text { dos processos existentes na indústria do vestuário, com amplo } \\
\text { foco no desenvolvimento de produto. Há menção sobre a } \\
\text { utilização de matérias-primas e o armazenamento, bem como } \\
\text { sobres os calendários específicos de lançamento do produto. }\end{array}$ & Livro \\
\hline $\begin{array}{l}\text { Shaw e Koumbis } \\
(2014)\end{array}$ & $\begin{array}{l}\text { Discorrem sobre o processo de compras, detalhadamente com } \\
\text { as especificidades do mercado da moda. Apesar de uma } \\
\text { abordagem específica não tratam sobre o contexto das } \\
\text { indústrias e sim sobre redes de varejo. }\end{array}$ & Livro \\
\hline $\begin{array}{l}\text { Tacconi et al., } \\
\qquad(2014)\end{array}$ & $\begin{array}{l}\text { Abordam sobre a importância do setor de compras com ênfase } \\
\text { nas relações de parceria que devem ser criadas entre } \\
\text { empresas fornecedoras e geradoras de demanda, de modo } \\
\text { geral. }\end{array}$ & Artigo \\
\hline $\begin{array}{l}\text { Čiarniené e } \\
\text { Vienažindienéb } \\
(2014)\end{array}$ & $\begin{array}{l}\text { Propõem uma discussão em torno da indústria da moda e a } \\
\text { necessidade da rápida tomada de decisões, junto a cadeia de } \\
\text { produção fast fashion. Deste modo discutem ações a serem } \\
\text { tomadas na cadeia de suprimentos que auxiliam na } \\
\text { organização dos demais processos produtivos. }\end{array}$ & Artigo \\
\hline $\begin{array}{l}\text { Turker e Altuntas } \\
\qquad(2014)\end{array}$ & $\begin{array}{l}\text { Analisam estratégias utilizadas por empresas de vestuário para } \\
\text { garantir a qualidade dos produtos por meio da gestão da cadeia } \\
\text { de suprimentos. Para isso analisam a indústria do vestuário e } \\
\text { critérios de fornecimento que mantêm a cadeia de suprimentos } \\
\text { sustentável. }\end{array}$ & Artigo \\
\hline $\begin{array}{l}\text { Andrade, Bezerra } \\
\text { e Ladim (2015) }\end{array}$ & $\begin{array}{l}\text { Tem o objetivo de apresentar o funcionamento da indústria do } \\
\text { vestuário e contextualizar o cenário atual do setor. }\end{array}$ & Artigo \\
\hline $\begin{array}{l}\text { Yang, Qi e Li } \\
\quad(2015)\end{array}$ & $\begin{array}{l}\text { Estudam o impacto da rápida tomada de decisões no } \\
\text { desempenho da cadeia de fornecimento em cadeias } \\
\text { descentralizadas. }\end{array}$ & Artigo \\
\hline $\begin{array}{l}\text { Mondini et al., } \\
\quad(2015)\end{array}$ & $\begin{array}{l}\text { Apresentam uma discussão sobre o planejamento de compras } \\
\text { e o impacto que isso acarreta no desempenho financeiro da } \\
\text { empresa. Para isso mostram o papel estratégico e necessário } \\
\text { desse setor nas atividades de empresas de transformação. }\end{array}$ & Artigo \\
\hline $\begin{array}{l}\text { Delalibera, Lima } \\
\text { e Turrioni (2015) }\end{array}$ & $\begin{array}{l}\text { Discorrem sobre o gerenciamento da cadeia de suprimentos } \\
\text { com foco nas relações que nela são estabelecidas, de modo a } \\
\text { assegurar a competitividade, consideram a importância em } \\
\text { termos de valor que a matéria-prima representa para as } \\
\text { empresas - de diferentes tipos de negócios. }\end{array}$ & Artigo \\
\hline $\begin{array}{l}\text { Hallikas e } \\
\text { Lintukangas } \\
\quad(2016)\end{array}$ & $\begin{array}{l}\text { Discutem o gerenciamento do risco de fornecimento, deste } \\
\text { modo abrangem sobre a cadeia de fornecimento, a relação com } \\
\text { os fornecedores, apresentando como o processo de compras } \\
\text { intervêm no risco de fornecimento, para as empresas. }\end{array}$ & Artigo \\
\hline Silva (2017) & $\begin{array}{l}\text { Ao tratar elementos de Gestão do Conhecimento no processo } \\
\text { de compras em empresas do setor do vestuário, descreve esse } \\
\text { processo e as relações entre demais setores que compõem o } \\
\text { processo produtivo. }\end{array}$ & Dissertação \\
\hline $\begin{array}{l}\text { Silva et al., } \\
\quad(2018)\end{array}$ & $\begin{array}{l}\text { Apresentam elementos de Gestão do Conhecimento no } \\
\text { processo de compras de uma empresa de moda e vestuário. } \\
\text { Descrevem os setores que mantêm relações de trabalho } \\
\text { juntamente à área de compras, nessa empresa. }\end{array}$ & Artigo \\
\hline
\end{tabular}

Fonte: Elaborado a partir dos dados da pesquisa (2017).

Conforme apresentado no Quadro 1, nem todas as publicações são específicas sobre indústrias do vestuário, contudo são necessárias para 
compreender especificidades existentes na cadeia de suprimentos e, o papel do setor de compras para a estrutura de negócios das empresas de modo geral. Diante do exposto observa-se discussões em torno da importância estratégica do setor de compras, da necessidade da rápida tomada de decisões na cadeia de suprimentos, a avaliação das decisões tomadas no fornecimento e descrição dos processos existentes no contexto do vestuário ou relações com a área de compras, como tratado por Andrade, Bezerra e Ladim (2015), Silva (2017), Silva et al., (2018).

Os materiais descritos no Quadro 1, foram utilizados para compor o referencial teórico deste trabalho e partir da leitura dos mesmos e diante da necessidade de estudos específicos para a área da moda e do vestuário, e considerando o objetivo desta pesquisa, foi elaborado um esquema que analisa como o processo de compras está inserido no ciclo produtivo da indústria do vestuário e após isso analisa as relações existentes com os setores ou processos descritos nesse esquema.

A elaboração do esquema, por meio de uma figura, não priorizou destacar as atividades básicas dos setores ou até mesmo do setor de compras, mas sim apresentar as atividades gerais do processo de desenvolvimento de produto, que contribui para entender o ciclo produtivo da indústria do vestuário. Para estabelecer quais seriam essas atividades foi analisado primeiramente os processos existentes na indústria do vestuário descritos por Jones (2005), Rech (2008), Treptow (2013), Andrade, Bezerra e Ladim (2015), Silva (2017) e Silva et al., (2018). Em consonância com o referencial teórico e com o objetivo da pesquisa estabeleceu-se como setores fundamentais do processo produtivo da indústria do vestuário: criação; modelagem; prototipagem; compras; almoxarifado; PCP; produção e; comercial.

Os processos aqui elencados contemplam desde o momento da pesquisa até o lançamento do produto para venda. Apresenta o que acontece, de modo geral, em cada processo ou atividade e onde há incidência de atividade conjunta desenvolvida com o setor de compras. O esquema elaborado é apresentado na Figura 1. 
Figura 1 - Esquema sobre a inserção do processo de compras no ciclo produtivo da indústria do vestuário

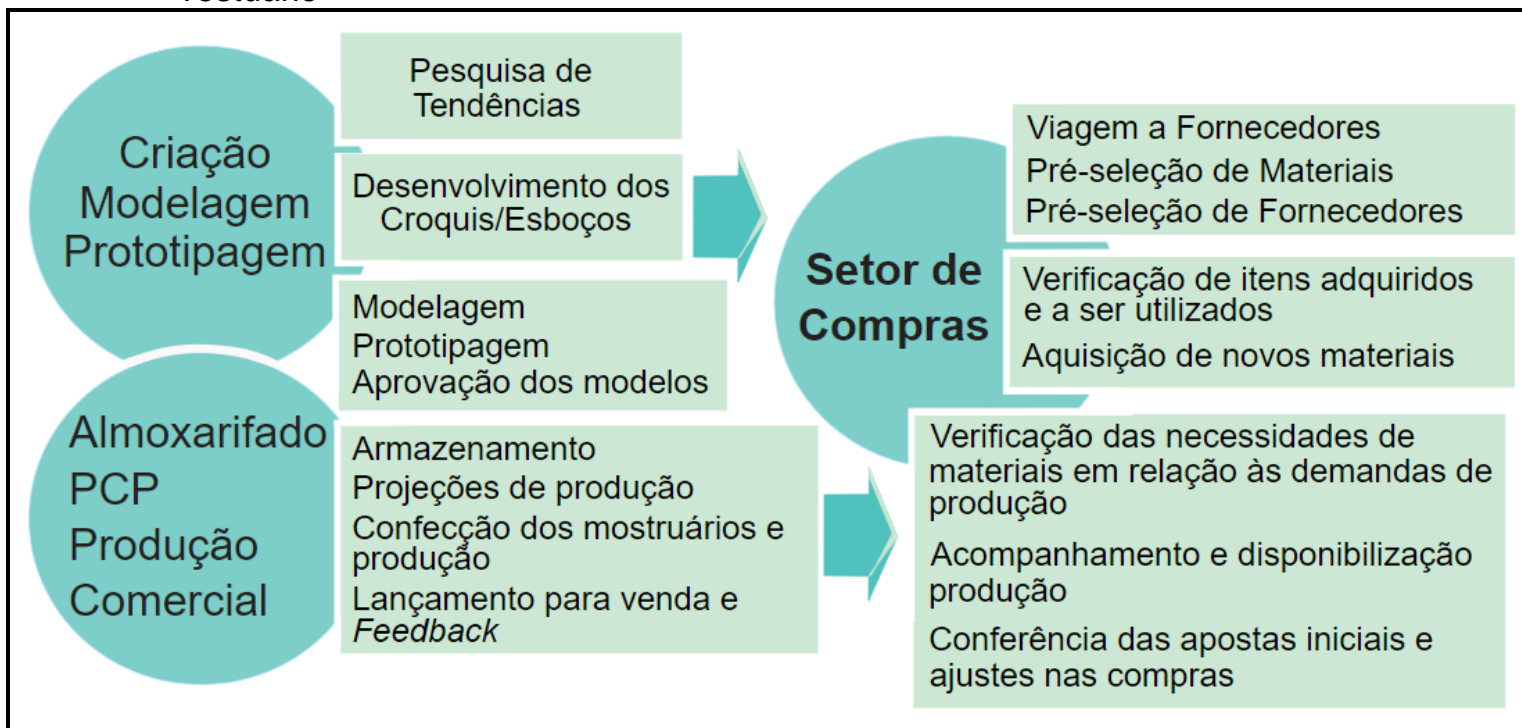

Fonte: Elaborado a partir das contribuições de Jones (2005), Rech (2008), Treptow (2013), Andrade, Bezerra e Ladim (2015), Silva (2017) e Silva et al., (2018).

A Figura 1 considera as principais atividades realizadas pelos setores fundamentais existentes nas indústrias de vestuário - considerando que apesar do porte ou tipo de comercialização, essas atividades são básicas para o setor de vestuário - sendo a criação, modelagem, prototipagem, compras, almoxarifado, PCP, produção (contendo os processos de risco, enfesto, corte, costura e acabamentos) e o comercial. Não se prioriza mencionar qual setor está ligado ou subordinado a qual, mas sim dentro de um processo geral apresentar atividades realizadas em conjunto com o setor de compras.

Shaw e Koumbis (2014), Tacconi et al., (2014), Cipriani Jr et al., (2015), Delalibera, Lima e Turrioni, (2015) indicam que as relações de parcerias são necessárias para o desenvolvimento estratégico da cadeia de suprimentos, as relações apresentadas na Figura 1 mostram-se como fundamentais para as empresas de vestuário. O que se pode identificar é que durante a fase de desenvolvimento (criação, modelagem e pilotagem) acontece por parte do setor de criação o início das pesquisas de tendências e a busca dos materiais a serem utilizados - essa busca envolve encontrar os fornecedores capazes de fornecer os produtos necessários. Nesse período pode ocorrer, por parte do setor de compras, viagens a fornecedores para auxiliar na busca desses materiais, que pode ou não ser em conjunto com os estilistas (JONES, 2005; SILVA, 2017; SILVA et al., 2018). 
Ainda, na fase de desenvolvimento - durante a criação dos croquis, modelagem e prototipagem -, há uma pré-seleção de materiais e fornecedores, aquisição de novos materiais e análise de estoques. Durante a prototipagem - que é a confecção do primeiro modelo - caso haja alguma inconsistência na qualidade dos materiais o setor de compras deve ser avisado e promover as soluções cabíveis junto ao fornecedor, troca, cancelamento ou devolução do material, isso irá evitar a aquisição de materiais inadequados para a produção (SILVA, 2017; SILVA et. al., 2018). No que se refere às atividades dos setores de almoxarifado, PCP, produção e comercial, é onde realmente há a efetivação das previsões e da confecção dos produtos.

Em relação ao almoxarifado, que é o responsável pelo recebimento e armazenamento dos materiais, há informações sobre a condição de chegada do produto, o PCP é o responsável por gerar as demandas de produção, sejam essas por previsões - quando há necessidade de produzir antes da venda ou para abastecer as células de produção, nos períodos de transição de coleções - ou por efetivação - quando há produtos vendidos e são necessárias conferências das programações já realizadas. Ou seja, esses setores necessitam tanto receber informações da área de compras quanto abastecer o mesmo com informações que são necessárias para as atividades relacionadas a aquisição (SILVA, 2017; SILVA et. al., 2018).

A produção em si pode criar informações sobre a necessidade de determinados materiais, ou é nessa etapa que podem surgir problemas com algum produto no processo de costura, por exemplo. O comercial possui informações sobre as vendas, e isso contribui para a certeza na aquisição antecipada de itens, por exemplo, já que uma coleção pode respaldar as decisões das próximas. Esses dois setores apresentam uma relação menor do que os anteriores, mas não menos importante (HALLIKAS; LINTUKANGAS, 2016; SILVA, 2017; SILVA et. al., 2018).

Ao que se observa retomando o objetivo desta pesquisa que é analisar como o processo de compras está inserido no ciclo produtivo da indústria do vestuário e se há relações existentes com outros processos, a Figura 1 mostra que o processo de compras está inserido principalmente na troca de informações e em ações que validam o trabalho de outros setores. As relações existentes são principalmente entre a criação, PCP e almoxarifado e em menor passo com a produção e com o 
comercial.

Delalibera, Lima e Turrioni (2015) apresentam a ideia de que o gerenciamento e a atenção adequada à área de compras tornam a empresa competitiva e consequentemente traz melhores retornos aos acionistas. Neste sentido, a proposta do esquema apresentado na Figura 1, confirma que as relações entre os setores internos são fundamentais para a organização do processo produtivo e pode contribuir para outras análises que permeiam essa mesma problemática.

As afirmações encontradas na pesquisa, sobre a fragmentação dos processos, dificuldade em elencar esses processos, necessidade de parcerias e importância estratégica da área de compras, foram confirmadas a partir da discussão aqui apresentada.

\section{CONSIDERAÇÕES FINAIS}

Apesar da representatividade que o setor do vestuário possui na economia tanto do Brasil quanto de outros países, observa-se falta de discussões teóricas acerca de seus processos produtivos e a melhoria desses processos. Essas discussões tendem a contribuir para soluções ou novas visões sobre as etapas produtivas de modo a promover a inovação não só dos produtos, mas também no que se refere aos sistemas de produção. Acredita-se que as discussões em torno dessa temática contribuam para expandir o conhecimento e aprofundar o que já vem sendo discutido pela literatura.

Dentre os diferentes setores que compreendem a estrutura produtiva de uma empresa de vestuário, o de compras é o responsável por adquirir, negociar e gerenciar a disposição dos produtos que serão utilizados na produção. O processo de compras não é realizado de forma individual, mesmo que se perceba que nesse tipo de indústria possa haver autonomia por parte de alguns setores, entre eles o de compras. Percebeu-se a necessidade de se estabelecer parcerias, internas e externas, como setores afetos ao processo de compras e fornecedores de materiais e serviços, essas parcerias são fundamentais para uma cadeia de abastecimento enxuta e flexível, que atenda às especificidades do setor do vestuário.

Em se tratando de indústrias do vestuário, verificou-se que essas são compostas de instabilidade, efemeridade de produtos, curto ciclo produtivo e de 
produtos, grande número de informações em trânsito e fragmentação de processos. Esse cenário se mostra como de difícil identificação dos setores e processos que compõem o processo produtivo da indústria do vestuário, que há a necessidade de antecipação de processos de produção para atender aos prazos e que a aquisição e chegada das matérias-primas são fundamentais para que esse processo ocorra sem paradas de produção, aquisição de materiais desnecessários e produção de produtos que não serão entregues.

Afirma-se então que o setor de compras é de grande importância estratégica para as indústrias de vestuário, apesar desse processo nesse contexto ser pouco explorado pela literatura. Ao verificar os processos ou setores envolvidos no processo produtivo da indústria do vestuário e a relação com o setor de compras descobriu-se primeiramente que há lógicas de produção, sendo que a nomenclatura e quantidade de processos ou setores pode variar de acordo com o porte ou tipo de venda. Contudo descobriu-se que há processos considerados básicos nessas empresas, independente desses dois fatores, sendo: criação; modelagem; prototipagem; compras; almoxarifado; PCP, produção e comercial.

Entre as atividades executadas pelo setor de compras, em empresas de vestuário, estão a busca por fornecedores que disponham de materiais que serão utilizados pelo setor de criação, o controle da chegada e da qualidade desses materiais - no caso de materiais em não conformidade, acionam os fornecedores para providências - aquisição dos materiais por meio de previsões, que podem ser feitas somente pelo setor de PCP ou em conjunto entre os setores, conferência dos itens já adquiridos e a adquirir e, o controle dos níveis de inventário. Atrela-se a isso as atividades básicas, como emissão de pedidos, negociação, baixa de ordens de compras entre outros.

Por fim conclui-se que, os estudos que abordam a problemática em torno do setor de compras em empresas de vestuário necessitam de análises mais densas, podendo este estudo ser utilizado como base para verificação em campo e avaliação dos resultados que possam ser encontrados.

\section{REFERÊNCIAS}


têxtil e de confecção aponta sinais positivos para 2017. Disponível em: http://www.abit.org.br/noticias/setor-textil-e-de-confeccao-aponta-sinais-positivospara2017. Acesso em: 24 maio 2017.

BRUCE, Margaret; DALY, Lucy; TOWERS, Neil. Lean or agile: a solution for supply chain management in the textiles and clothing industry. International journal of operations \& production management, v. 24, n. 2, p. 151-170, 2004. https://doi.org/10.1108/01443570410514867

CIPRIANI JR, V.; CRACO, T.; CAMARGO, M. E.; BIEGELMEYER, U. H. A evolução da área de compras em uma empresa do ramo moveleiro como uma forma de ampliar a sua competitividade. Revista Espacios, n. 36, n. 10, p. 8, 2015.

ČIARNIENĖ, R.; VIENAŽINDIENĖB, M. Agility and Responsiveness Managing Fashion Supply Chain. Procedia - Social and Behavioral Sciences, v. 150, p. 1012-1019, Sep. 2014. https://doi.org/10.1016/..sbspro.2014.09.113

DELALIBERA, P.H.A.; LIMA, R.S.; TURRIONI, J.B. Pesquisa levantamento para análise do modelo de compras conjuntas adotado em arranjos produtivos locais de Minas Gerais. Production, v. 25, n. 2, p. 391-402, 2015. https://doi.org/10.1590/01036513.014411

HALLIKAS, J.; LINTUKANGAS, K. Purchasing and supply: An investigation of risk management performance. International Journal of Production Economics, $v$. 171, part 4, p. 487-494, Jan. 2016. https://doi.org/10.1016/j.ijpe.2015.09.013

JONES, S. J. Fashion design: manual do estilista. Cosac Naify: São Paulo, 2005.

KACHBA, Y. R.; HATAKEYAMA, K. Competence for Product Development Management in Clothing Firms. International Association for Management of Technology. IAMOT, p. 1863-1876, 2015. Disponível em:

http://www.iamot2015.com/2015proceedings/documents/P253.pdf. Acesso em: 25 ago. 2016.

LIMA, F. de S.; PAZ, N. K. da S.; COSTA P. V. M.; CRUZ, M. A. P. da. Análise da eficácia do processo de compras. Revista Inova Ação, Teresina, v. 1, n. 1, art. 7, p. 71-78, jan./jun. 2012.

MACCHION, L.; MORETTO, A.; CANIATO, F.; CARIDI, M.; DANESE, P.; VINELLI, A. Production and supply network strategies within the fashion industry.

International Journal of Production Economics, v. 150, p. 1012-1019, Sep. 2014.

MONDINI, L. C.; MACHADO, D. D. P. N.; SCARPIN, M. R. S.; MONDINI, V. E. D. Impacto do planejamento de compras no desempenho financeiro da indústria de transformação do Brasil. REAd - Revista Eletrônica de Administração, Porto Alegre, v. 1, n. 80, p. 113-140, jan./abr. 2015. https://doi.org/10.1590/1413$\underline{2311.0292014 .50270}$

MOON, K. K. L.; YI, C. Y.; NGAI, E. W. T. An instrument for measuring supply chain flexibility for the textile. European Journal of Operational Research, v. 222, n. 2, p. 
315-664, Oct. 2012. https://doi.org/10.1016/j.ejor.2012.04.027

PICKLES, J.; PLANK, L.; STARITZ, C.; GLASMEIER, A. Trade policy and regionalisms in global clothing production networks. Cambridge Journal of Regions, Economy and Society, v. 8, n. 3, p. 381-402, 2015.

https://doi.org/10.1093/cjres/rsv022

$\mathrm{POZO}, \mathrm{H}$. Administração de recursos materiais e patrimoniais: uma abordagem logística. 4. ed. Atlas, São Paulo, 2007.

$\mathrm{RECH}$, Sandra Regina. Estrutura da cadeia produtiva da moda. ModaPalavra eperiódico, v. 1, n. 1, p. 7-20, jan./jul. 2008.

SCHOENHERR, T.; MODI, S. B.; BENTON, W. C.; CARTER, C. R.; CHOI, T. Y.; LARSON, P. D.; LEENDERS, M. R.; MABERT, V. A; NARASIMHAN, R., WAGNER, S. M. Research opportunities in purchasing and supply management. International Journal of Production Research, v. 50, n. 16, p. 4556-4579, Aug. 2012. https://doi.org/10.1080/00207543.2011.613870

SEN, A. The US Fashion Industry: A supply chain review. Int. J. Production Economics, p. 571- 593, 2008. https://doi.org/10.1016/j.ijpe.2007.05.022

SHAW, D.; KOUMBIS, D. A compra profissional de moda. 1. ed. Trad. Márcia Longarço. São Paulo, Gustavo Gili, 2014.

SILVA, M. J. A Gestão do Conhecimento no processo de compras de matériasprimas e complementos em uma empresa do setor de moda e vestuário da região Noroeste do Paraná. 128 f. (Dissertação Mestrado) - Programa de PósGraduação em Gestão do Conhecimento nas Organizações. Centro Universitário de Maringá. Maringá, 2017.

SILVA, M. J.; MENEGASSI, C. H. M.; SARTORI, R.; TENÓRIO, N. Knowledge management within the fashion and clothing industry: an investigation into the purchase processes within a company. International Journal of Development Research, v. 08, n. 03, p. 19739-19743, mar. 2018.

TACCONI, M. D. F. F. D. S. LOPES, F. D.; MOL, A. L. R.; NETO, E. A. T. A confiança interorganizacional nas compras. Gestão da Produção, São Carlos, v. 21, n. 1, p. 199-214, 2014. https://doi.org/10.1590/S0104-530X2014000100014

TOSETTI, S.; PATIÑO, D.; CAPRARO, F.; GAMBIER, A. Control of a production inventory system using a PID controller and demand prediction. The International Federation of Automatic Control, p. 1869-1874, Jul. 2008. Disponível em: http://www.nt.ntnu.no/users/skoge/prost/proceedings/ifac2008/data/papers/3860.pdf.. Acesso em: 16 fev. 2018. https://doi.org/10.3182/20080706-5-KR-1001.00319

TREPTOW, D. Inventando moda: planejamento de coleção. 5. ed. São Paulo: Edição da Autora, 2013. 
TURKER, D.; ALTUNTAS, C. Sustainable supply chain management in the fast fashion industry: An analysis of corporate reports. European Management Journal, v. 32, n. 5, p. 837-849, Oct. 2014. https://doi.org/10.1016/.emi.2014.02.001

TYLER, D.; HEELEY, J.; BHAMRA, T. Supply chain influences on new product development in fashion clothing. Journal of Fashion Marketing and Management: An International Journal, v. 10, n. 3, p. 316-328, 2006. https://doi.org/10.1108/13612020610679295

YANG, D.; QI, E.; LI, Y. Quick response and supply chain structure with strategic consumers. Omega, v. 52, p. 1-14, Apr. 2015.

https://doi.org/10.1016/i.omega.2014.10.006

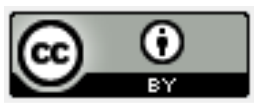

Artigo recebido em: 09/08/2018 e aceito para publicação em: 05/12/2020

DOI: http://dx.doi.org/10.14488/1676-1901.v20i4.3342 